\title{
STUDIES WITH CULTURED HUMAN EPIDERMAL KERATINOCYTES: POTENTIAL RELEVANCE TO CORNEAL WOUND HEALING
}

\author{
FIONA M. WATT \\ London
}

Human epidermal cells (keratinocytes) can be grown in culture under conditions in which they form stratified sheets with the same basic characteristics as the tissue from which they are derived. ' Proliferation takes place in the basal layer and cells which have left that layer undergo terminal differentiation as they move through the suprabasal layers; eventually, dead cornified squames detach into the culture medium. The availability of human keratinocyte cultures has allowed us to investigate the factors that regulate keratinocyte growth, differentiation and stratification.

Recent evidence points to a role of adhesive receptors of

Correspondence to: Fiona M. Watt, Keratinocyte Laboratory, Imperial Cancer Research Fund, Lincoln`s Inn Fields, London WC2A 3PX, UK the integrin family in regulating many aspects of keratinocyte behaviour. ${ }^{2}$ Integrins are heterodimers, each consisting of an $\alpha$ and a $\beta$ subunit. The integrins expressed by keratinocytes include $\alpha_{2} \beta_{1}$ (receptor for collagen and laminin), $\alpha_{3} \beta_{1}$ (receptor for epiligrin and laminin), $\alpha_{5} \beta_{1}$ (fibronectin receptor), $\alpha_{\mathrm{v}} \beta_{5}$ (vitronectin receptor) and $\alpha_{6} \beta_{4}$ (component of hemidesmosomes; may be a laminin receptor). The keratinocyte integrins not only mediate adhesion of basal cells to the underlying basement membrane, but also play a role in lateral cell migration and stratification and regulate the onset of terminal differentiation. Furthermore, the basal keratinocytes with the highest proliferative potential (stem cells) can be distinguished from other proliferative cells (transit amplifying cells) because they express higher levels of the $\beta_{1}$ integrins. ${ }^{3}$ Fig. 1 shows the

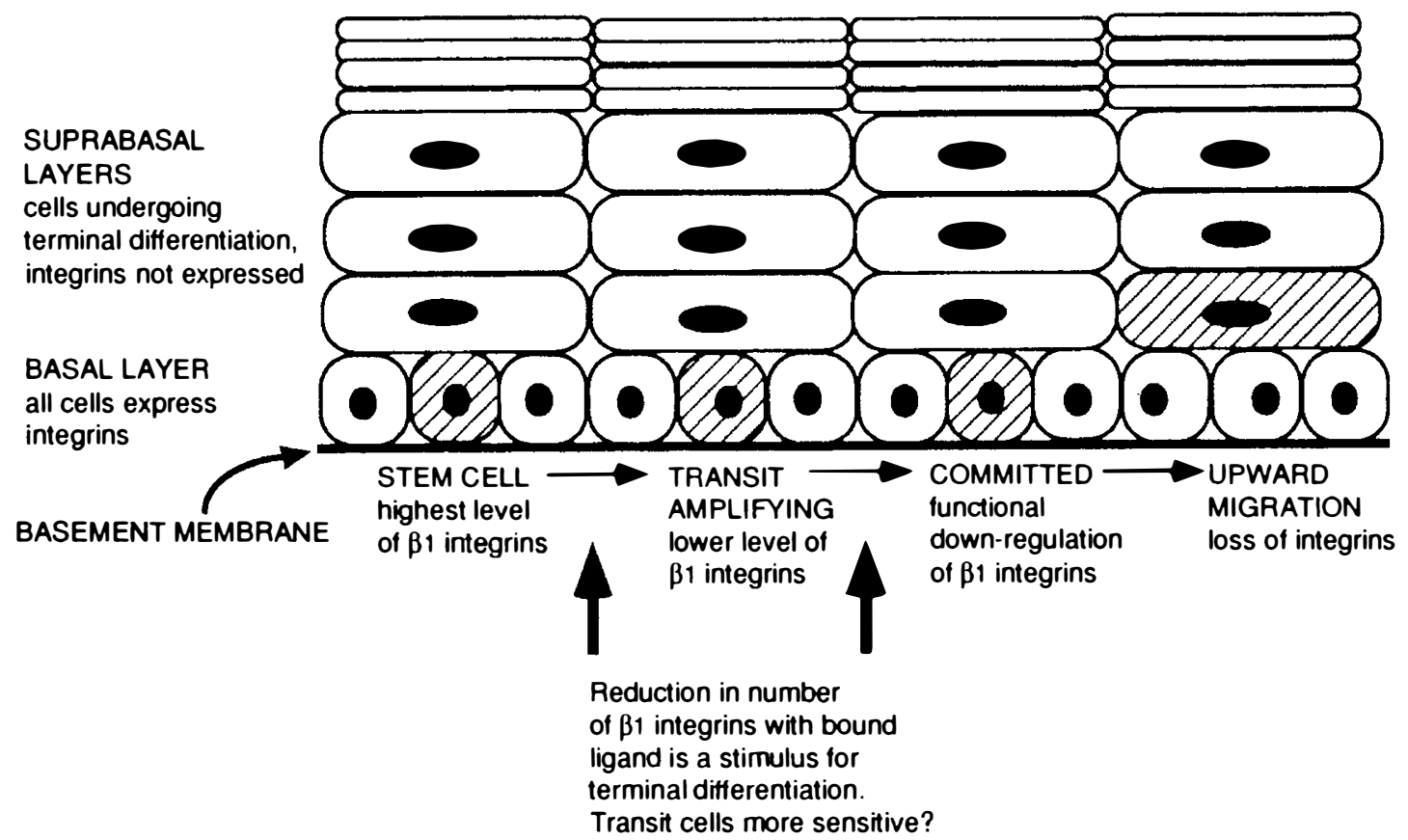

Fig. 1. Model of the relationship between keratinocyte adhesiveness, proliferation and terminal differentiation. (Reproduced from Jones and Watt ${ }^{3}$ with permission. (C) Cell Press.)

Eye (1994) 8, 161-162 C 1994 Royal College of Ophthalmologists 
proposed sequence of events within the epidermal basal layer by which a stem cell generates a suprabasal, terminally differentiating daughter.

Given the important functions of the keratinocyte integrins, it is not surprising that integrin expression is perturbed during wound healing and in a number of benign and neoplastic disorders of keratinocytes. Integrin expression is normally confined to the basal layer of the epidermis, but during epidermal wound healing, in psoriatic epidermal lesions and in dysplastic and hyperplastic lesions of the oral cavity pronounced suprabasal expression is observed. ${ }^{4.5}$ Integrin expression patterns in squamous cell carcinomas are variable, but focal or extensive loss of specific integrin subunits is a common feature of poorly differentiated oral squamous cell carcinomas. ${ }^{5}$

What relevance might these observations have for corneal wound healing? Human corneal epithelial cells can be grown in culture using the same techniques as those for culturing epidermal keratinocytes, ${ }^{6}$ and the integrins expressed by corneal and epidermal keratinocytes are similar. ${ }^{7}$ It is thus both worthwhile and feasible to investigate the role of integrins in regulating corneal epithelial cell growth, differentiation and wound healing.
Key words: Adhesion, Differentiation, Integrins, Stem cells, Neoplasia.

\section{REFERENCES}

1. Watt FM. Terminal differentiation of epidermal keratinocytes. Curr Opin Cell Biol 1989;1:1107-15.

2. Watt FM, Hertle MD. Keratinocyte integrins. In: Leigh IM, Lane EB, Watt FM. The keratinocyte handbook. Cambridge: Cambridge University Press 1994 (in press).

3. Jones PH, Watt FM. Separation of human epidermal stem cells from transit amplifying cells on the basis of differences in integrin function and expression. Cell 1993;73:713-24.

4. Hertle MD, Kubler M-D, Leigh IM, Watt FM. Aberrant integrin expression during epidermal wound healing and in psoriatic epidermis. J Clin Invest 1992;89:1892-1901.

5. Jones J, Sugiyama M, Watt FM, Speight PM. Integrin expression in normal, hyperplastic, dysplastic, and malignant oral epithelium. J Pathol 1993;169:235-43.

6. Sun T-T, Green H. Cultured epithelial cells of cornea, conjunctiva and skin: absence of marked intrinsic divergence of their differentiated states. Nature 1977;269:489-93.

7. Stepp MA, Spurr-Michaud S, Gipson IK. Integrins in the wounded and unwounded stratified squamous epithelium of the cornea. Invest Ophthalmol Vis Sci 1993;34:1829-44. 